\title{
Stress and Social Conflict Management in An Organization
}

\author{
Dr. Ben Ohuruogu \\ Ebonyi State University, Abakaliki, Nigeria \\ Alor Roseline Chinyere. \\ Ebonyi State College of Education, Ikwo, Ebonyi, Nigeria \\ Ogbonna Raphael Nwodeh \\ Ebonyi State College of Education, Ikwo, Ebonyi, Nigeria \\ Mkpuma Solomon Okechukwu \\ Ebonyi State College of Education, Ikwo, Ebonyi, Nigeria \\ Akpagu Cletus Ikechukwu \\ Enugu State University of Science and Technology
}

\begin{abstract}
Stress is a state of mental or emotional strain or tension resulting from adverse or demanding circumstances. It is a reaction that result when people are unable to effectively and efficiently manage hazards they are presented with, while social conflict refers to a situation in which the parties are an aggregate of individual, such as groups, organization, communities crowd, rather than single individuals as in role conflict. The paper discussed stress and social conflict in an organization ranging from personal, intergroup and intergroup conflicts, relationship at work and organization culture. It also discussed the causes of stress and social conflict among workers. The paper also looked at stress and social conflict management and prevention methods adopted in an organization. The paper recommended among others that organizations should be proactive in developing preventive and management strategies into combating work related stress and social conflict.
\end{abstract}

Keywords: Stress, Social Conflict, Management Strategies, Organization

DOI: $10.7176 / \mathrm{JNSR} / 10-6-03$

Publication date:March $31^{\text {st }} 2020$

\section{Introduction}

Workers in an organization are under constant pressure from their boss to do a good job. Athletes in sports setting try very hard to improve their performance. Spectators get caught up in the excitement of their team's attempt to win the championship, all the people in the above examples face very different situations, but they share one thing in common. They are all experiencing stress. Stress according to Patrick (2008) is the psychological strain or distress resulting from exposure to unusual or demanding situations, known as stressors. Stress is any action or situation that places special physical or psychological demands upon an individual. It is also construed as a bodily reaction that occurs in response to either internal or external stimuli.

Generally, stress is a stimulus or succession of stimuli of such magnitude as it tends to disrupt the homeostatis of the organism. It is related to fear, anger and pain. Organizational conflict or workplace conflict, is a state of discord caused by the actual or perceived opposition of needs, values and interests between working together (Beoling and Beehr, 2006). Organizational conflict takes many form ranging in evitable class between formal authority and power and those individuals and groups affected. There are disputes over how revenues should be divided, how work should be done, and how long and hard people should work. There are jurisdictional disagreements among workers and managements. There are subtler forms of social conflict involving rivalries, jealousies, personality clashes, role definitions and struggles for power and favour. There is also conflict within individuals, between competing needs and demands, to which individuals respond in different ways. All these social conflicts are as a result of stress.

Job stress takes basically two forms; Job ambiguity and job conflict. Ambiguity refers to the lack of clarity surrounding a person's job authority, responsibility, task demands, and work methods. If a job is ambiguous, the worker has unclear work goals, procedures, and responsibilities and may be uncertain about his or her authority. The person suffering from job ambiguity simply does not know what is expected in terms of job performance.

Job conflict therefore refers to the degree of incompatibility of expectations felt by a person on the job. In common sense, a person is caught in a decision quandary. A worker experiences job conflict when the worker must choose to do one thing over another and feels uneasy. For example, an employee may be reporting to the plant manager and at the same time to another manager with functional authority, each of whom wants the employee to follow two different orders. Each may ask the employee to do a different thing within the same time 
frame. The worker will be in a dilemma on whose orders to follow. Another conflict arises when people are asked to perform duties for which they were not hired to do or when a employee is ordered to perform duties which seem unethical, if the duties are actually performed, the person may suffer from guilt feelings and depression from having sacrificed strongly held up principles, reducing job stress. In any formal relationship leaders and followers interact this is bound to be disagreement. When the parties are nearly of equal strength, conflict generally ends in a relatively satisfactory compromise, but in a superior-subordinate relationship, compromise is not always possible or practicable. Generally, this kind of conflict is detrimental to organizational climate and could cause the climate top minimize the harmful effects of conflict and seek to take advantage of the possible positive benefits. When or not conflict can be controlled depends upon the cause of the conflict. The issues, which are the causes of conflict can be broken down into substantive issues and emotional issues substantive issues stem from differing viewpoints about policies, organizational structure, operational practices, and role relationships, Francis and Milbourn Jr (1980). Emotional issues are more personal in nature and involve feelings of distrust, rejection, fear, resentment and/or anger. Since it is easier to control and to resolve conflicts caused by substantive issues, the emotional issues must be viewed as being the most detrimental to organizational climate. Although, it is not possible to completely eliminate conflict, it is possible for managers to create an environment or climate wherein conflict can be controlled so that there may be possible contribution to the existing climate.

\section{Organization, Stress and Social Conflict}

Health and Safety Executive (2000) described organization as a system of roles. They maintained that each member of the organization belongs to a role set, which is an organization of individuals who share interdependent tasks and thus perform formally defined roles, which are further influenced both by the expectations of others in the role set and by one's own personality and expectations.

Scott, (1998) defined organization as an entity comprising multiple people, such as an institution or an association, that has a collective goal and is linked to an external environment. Thus organization may mean sports organization in an institution or an organization:

Karasek, (1990) defined stress as the psychological strain or distress resulting from exposure to unusual or demanding situations known as stressors. Stress is best seen as pressures and demands put on individual and maladaptive responses of individual like anxiety, irritability, aches and pains, an interaction between situational demands and the resources of the individual to cope with them.

While conflict It is state of discord caused by the actual or perceived opposition of needs, values and interests between people working together, (Conflict Resolution principles (2012).

Conflict management according to Evans and Newnham (1992) implies any situation whereby the worst excesses of conflict are avoided or mitigated, while to Mhehe (1997) it entails the ability to handle every day situation that involves differences in opinion.

Conflict management is the process by which appropriates and techniques are introduced in an organization to control conflicts (Mukoro and Mukoro, 2006) in the same vain, Homes (2010) defined management as a systematic process geared toward finding mutually satisfying outcomes. He observed that the ultimate purpose of conflict management is to reduce the incidence of dysfunctional conflicts and to increase the likelihood that any conflict that takes place will be managed efficiently and effectively.

Management conflict requires certain measures in order to achieve the expected outcome. Deetz and Stevenson (1986) stated a number of items that must be kept in mind when preparing for conflict management. Firstly, the manager must try to understand the type of conflict that he or she will be dealing with; identification of the type of conflict will help in managing the conflict. Secondly, the manager must also recognize the complexity of the conflict as this can vary widely and thirdly, the manager must be able to assess the energy and resources available for managing the conflict.

\section{Types of Social Conflicts among Workers in an Organization}

Social conflict affecting organizations can occur in individuals; between individuals and between groups. Social conflicts within work groups are often caused by struggles over control, status and scare resources. Social conflicts between groups in organizations also have similar origins. The constructive resolution of such conflicts can most often be achieved through a rational process of problem solving coupled with a willingness to explore issues and alternatives, and to listen to each other.

Liu, Spector \& Shi (2007) listed types of social conflicts in an organization to includes:

i. Personal Social Conflict: A personal social conflict involves a conflict between two people, most often from a mutual dislike or personality clash. Causes for workplace social/personal conflict can be personality or style differences and personal problems such as substance abuse, child care issues and family problems, organizational factors like leadership, management, budget and disagreement about core values can also contribute. Others causes are poor communication, different values, deferring interest, scare resources, personality clashes and poor performances. 
ii. Intragroup Social Conflict: This type of conflict arises in group because of the scarcity of freedom, position and resources. People who values independence tend to resist the need for interdependence and, to some extent, conformity within a group. People who seek power therefore struggle with others for position or status within the group. Rewards and recognition are often perceived as insufficient and improperly distributed, and members are inclined to compete with each other for these prizes.

iii. Intergroup Social Conflict: Intergroup social conflict occurs in four general forms. Horizontal strain involves competition between functions, for example, sales versus production, research and development versus engineering, purchasing versus legal, line versus staff and so on. Vertical strain involves competition between hierarchical levels, for example, union versus management, foremen versus middle management, shop workers versus foremen. A struggle between a group of employees and management is an example of vertical strain or conflict. A clash between a sales department and production over inventory policy would be an example of horizontal strain.

\section{Causes of Stress in an Organization}

Kagan, and Watson (1995) stated that unclear work or conflicting roles and boundaries cause stress, as can having responsibility for people. The responsibilities for job development are important buffers against current stress, with under promotion, lack of training, and job insecurity being stressful. Other sources of stress or buffers against stress are relationships at work, and the organizational culture. Managers who are critical, demanding, unsupportive or bullying create stress, where-as a positive social dimension of work and good team working reduces it.

An organizational culture of unpaid over-time or "presenteeism" causes stress. On the other hand a culture of involving people in decision, keeping them informed about what is happening in the organization, and providing good amenities and recreation facilities reduce stress. Such changes include mergers, relocation, restructuring or "downsizing" individual contracts, and redundancies within the organization.

Patrick (2008), sees passive aggressive behaviour as a common response from workers and managers which is particularly noxious to team unity and productivity. In workers, it can lead to sabotage of projects and the creation of a hostile environment. In managers, it can end up stifling a team's creativity.

Other causes of stress are office romance. This situation is very dangerous, because they can lead to conflict within the organization. Public displays of affection can make co-workers uncomfortable and accusations of favoritism may occur, especially, if it is a supervisor-subordinate relationship. If the relationship goes away, one party may seek to exact revenge on the other. Other causes of stress include:

1. Not knowing which tasks should assume priority and thus trying (unsuccessfully) to complete all of them simultaneously

2. Unclear job descriptions and organization charts/manuals leading to ambiguity about who should do what

3. Feelings of personal inadequately and insecurity

4. Frustrations at not being able to get things done.

5. Lack of communication with superiors, and conflicting demands placed on the individual by superiors who impose incompatible goals. For example, technical managers may demand high-quality output from certain insists that the head of the section drastically reduce its operating cost.

6. Bad personal relationships with other workers

7. Overwork, which may be quantitative (having too much work to do) or which may be quantitative (finding work too difficult) moreover, long working hours are frequently connected with a poor diet, lack of exercise and inadequate relaxation. Techniques and strategies useful for accommodating stress in an organization.

The first step is coping with stress in to recognize its inevitability in certain types of work: repression of anxiety only makes the situation worse. Therefore using the following techniques or strategies might help (1) Delegation of duties to subordinates to avoid work overload. (2) Deciding in advance when to withdraw from particularly stressful activities e.g making a conscious predetermined decision to leave a meeting if certain contentious issues are discussed or specifying maximum personal workload and never exceeding this. (3) Keeping a stress diary to record all stressful occurrences and hence identify common causes. (4) Conscious relaxation. (4)Training in personal assertive and/or psychological self-awareness methods such as transactional analysis (6) Restructuring in order to remove exceptionally stressful elements (which should then be redistributed equally among all the staff).

\section{Reducing Work Stress}

Factors and situations which create high levels of stress and conflict in an organization. Since, ambiguity and conflict leads to such unfavorable consequences as fatigue, anxiety, and low confidence in workers and in the organization, the cause of these problems must be determined and taken care of. Basically, organizational weakness which are in two categories such as organizational principles and supportive leadership. Good organizational principles and supportive leadership can serve to reduces and minimize the amount of job stress in 
the work environment viz.

1. Clear lines of authority: Clearly defined jobs, and participative goal setting will insure that workers understand their own goals as well those of the department and the organization. When theses are clearly defined, people will know what is expected of them in terms of their duties, authority, and responsibility. Such human problems as aimlessness and anxiety will not be where there is effective goal setting and a clear chain of command.

2. One supervisor per worker. The organizational principle prescribing that each worker should have one supervisor prevents a situation where a worker must try to fulfill the expectations of two supervisors an employee's efforts to appease as many people as possible sometimes results in several supervisors, giving him orders.

3. Responsibility equals authority: The organizational principles of "responsibility equaling authority" and having "authority delegated as far down the line as possible" insure that people fell important and significant to the firm while guaranteeing that employees are able to carry out their responsibilities without interferences as those involving overlapping authority. Many types of frustration and conflict result from being delegated authority for the success of an activity and then having it undetermined by the very person who delegated the authority in the first place. Employees must believe that delegated authentic and genuine of full commitment is expected from the subordinates.

4. The supportive leadership practices such as concern for personal development, team building, and friendliness. Insure that the workers feel appreciated as human beings. When workers know that their feelings and interest are important to top level managers, they will be less likely to feel stressful when problems are encountered. When employees know that managers are concerned with their development and have some tolerance for error, they will be better able to work creatively with less tension than when the organization is defensive, blame oriented and discoveraging.

\section{Consequences of Social Conflict on Workers in an Organization}

Unresolved social conflict in the workplace has been linked to miscommunication resulting from confusion or refusal to cooperate, quality problems, missed deadlines or delays, increased stress among employees, reduced creative collaboration and team problem solving, disruption to work flow, decreased customer satisfaction, distrust, split camps, and gossip. The followings are negative effects:

i. Divert time and energy from the main issues.

ii. Delay decisions

iii. Create dead locks

iv. Drive unaggressive committee members to the side lines

v. Interfere with listening

vi. Obstruct exploration of more alternatives decrease or destroy sensitivity

vii. Cause members to drop out or resign from committees

viii. Arouse anger that disrupts a meeting

ix. Interfere with empathy

$\mathrm{x}$. Incline underdogs to sabotage

xi. Provoke personal abuse

xii. Cause defensiveness.

\section{Social Conflict Management and preventions}

Several conflict management systems can be adopted in an organization, such as;

i. Improving organizational practices including establishing subordinate goals, reducing vagueness, minimizing authority and domain related disputes, improving policies, procedures and rules, re-apportioning existing resources or adding new, patterning communications, movement of personal and changing reward systems.

ii. Providing confidential advice to internal "customers" in relation to problems at work through human resources department of organizations.

iii. Counseling when personal conflict leads to frustration and loss of efficiency, counseling may prove to be a helpful antidote. Some organizations may have professional counselors to perform this function.

iv. Conflict avoidance: This involves non-attention or creating a total or partial separation of the combatants allowing limited interaction.

v. Smoothing: This implies stressing the achievement of harmony between disputants.

vi. Dominance or power intervention: It is the imposition of a solution by management at a higher level than the level of the conflict.

vii. Compromise: That is seeking a resolution satisfying at least part of each party's position.

viii. Confrontation: It is a thorough and frank discussion of the sources and types of conflict and achieving a resolution that is may be at the expense of one or all of the conflicting parties.

ix. Training helps prevent stress through becoming aware of the signs of stress, using this to interrupt behaviour patterns when the stress reaction is just beginning. Stress usually builds up gradually. The more stress build 
up, the more difficult it is dealt with, analyzing the situation and developing an active plan to minimize the stressors, learning skills of active coping and relaxation, developing a life style that creates a buffer against stress, practicing the above in low stress situations first to maximize chances of early success and boost self confidence and motivation to continue.

\section{Recommendations}

1. Organization should be proactive in developing preventive and management strategies in combating workrelated stress social conflict

2. Good organization principles and supportive leadership will reduce and minimize job stress in the work environment

3. Also removing job ambiguity and unclear job descriptions will also reduce social conflict and stress in an organization.

\section{REFERENCES}

Bowling, N. A \& Beehri, T. A. (2006). Workplace harassment from the victim's perspective: $A$ theoretical engineers, Journal of occupational Behaviour, 6 (2), 151 - 156.

Conflict Resolution Principles (2012). Supervisor Essentials Training TOOLINGU. Retrieved 1 December. 150.

Francis, G. J. and Milbourn G. J. (1980). Human behaviour in the work environment: A managerial perspective Goodyear publishing company inc. California, Santa Monica.

Health and Safety Executive, (2000). Organizational Interventions for work stress: a risk management approach. Norwich: Her majesty's stationary office: A thorough guide as to how to apply a risk management approach to work stress.

Kagan, N. I; Kagan, H; Watson, M.G. (1995). Stress reduction in the workplace: the effectiveness of psycho educational programs. J counsolling Psycholl: 42: 71-8.

Karase, K. R.A (1990). Theorell T. Healthy Work: Stress productivity and the reconstruction of working life. New York: Basic Books, A Seminal book that combines a clear theoretical and empirical approach to work stress.

Liu, C., Spector, P.E \& Shi, L. (2007). Cross-National Job Stress: A Quantitative and Q qualitative study. Journal of Organizational Behaviour, 28(2) 209 - 239.

Mhehe, E.G. (1997) The Role of the School Administration in conflict Management: "Position Paper (ED) 408642.

Patrick, J. Montana (2008). Management. New York: Barron's Educational Series, p265. ISBNO - 7641-3931-2. Scott, William Richard, (2008). Institutions and organization (3rd ed.) London: Sage Publications Ltd. ISBN 978$1-4129-5090-9$. 